\title{
Implications of ectomycorrhizal inoculation for drought stress tolerance of Atlas cedar (Cedrus atlantica (Endl.) Carrière) seedlings
}

\author{
Hamida Gaba Chahboub ${ }^{1 *}$, Mohamed Sghir Lamhamedi ${ }^{2}$ and Ouzna Abrous-Belbachir ${ }^{3}$ \\ ${ }^{1}$ National Forest Research Institute PO 37, Division of Forestry and Plant Breeding, Laboratory of Forest Ecophysiology. Cheraga, Algiers, Algeria \\ ${ }^{2}$ Forest Study Center, Laval University, 2325 University Street, Quebec, QC G1V QA6, Canada \\ ${ }^{3}$ University of Science and Technology Houari Boumedienne (USTHB) PO 32, Faculty of Biology, Laboratory of Biology and Physiology of \\ Organisms (LBPO), El Alia Algeria \\ *Corresponding author: chahboubhamida@yahoo.fr \\ (Received for publication 7 September 2020; accepted in revised form 23 June 2021)
}

\begin{abstract}
Background: Ectomycorrhizal inoculation is a promising strategy to minimise the initial transplant shock and increase plant survival and growth during the first years of out-planting in the field. The aim of this research was to investigate the effect of sporal inoculum of three ectomycorrhizal fungi: Cortinarius cedretorum, Amanita vaginata and Inocybe geophylla on tolerance levels of Atlas cedar (Cedrus atlantica (Endl.) Carrière) seedlings subjected to applied drought stress in nursery conditions.

Methods: Carpophores, seeds and organic forest soil were collected under pure stands of Atlas cedar. After fifteen months of growth, seedlings were subjected to drought stress by withholding water for thirty days; we assessed morphological and physiological variables of all seedling batches (inoculated and uninoculated, controlled and stressed seedlings)

Results: All roots of inoculated stressed seedlings were mycorrhizal. The mycorrhization rates were $67 \%, 64.6 \%$ and $53.6 \%$ for stressed seedlings inoculated with Cortinarius cedretorum, Amanita vaginata, Inocybe geophylla, respectively. This root mycorrhization was accompanied by a significant improvement in seedling growth, especially height and length of the main root $(10.2 \mathrm{~cm}, 52 \mathrm{~cm})$ reached in stressed seedlings inoculated with Cortinarius cedretorum. There was a significant increase in relative water content, total chlorophyll, carotenoids, soluble sugars and starch, superoxide dismutase and ascorbate peroxydase enzyme activities in inoculated stressed seedlings compared with uninoculated seedlings.

Conclusions: Inoculation of Atlas cedar seedlings with spores of ectomycorrhizal fungi remains a very effective alternative for improving growth and the morphological and physiological status of seedlings under drought conditions. Cortinarius cedretorum appears to be consistently advantageous followed by Amanita vaginata and Inocybe geophylla.
\end{abstract}

Keywords: Cedrus atlantica, drought stress, sporal inocula, forest soil.

\section{Introduction}

Atlas cedar (Cedrus atlantica (Endl.) Carrière) (Pinaceae) is an endemic species of the North African mountains in Algeria and Morocco. In Algeria, the cedar forest is found in both the Saharan and Tellian mountains where it represents $1.3 \%$ of the total forest area of the country (Belloula \& Beghami 2018). It has great ecological, floristic, socio-economic and heritage value to the local population (M'hirit \& Benzyane 2006). Prolonged episodic and recurrent droughts combined with high temperatures are among the main factors responsible for the physiological weakening of trees and increased vulnerability to other physiological decay processes (Ettobi et al. 2009, Kherchouche et al. 2013).

In North Africa, the success of reforestation programmes has become a major challenge because, after planting, seedlings are subjected to extreme environmental stresses (drought, high temperature, 
low soil fertility, etc.) during the establishment phase (Lamhamedi et al. 2000). The use of biological methods as a practical way to alleviate soil stresses, including drought, on plant growth has received increased attention (Miransari et al. 2009). Ectomycorrhizal inoculation is a promising strategy to minimise the initial transplant shock and increase plant survival and growth during the first years of out-planting in the field. (Boukcim et al. 2002). Ectomycorrhizal fungi can improve growth and physiological status of seedlings by enhancing their photosynthetic capacity and by increasing the uptake of water and mineral nutrients (Read et al. 2004), promote soil aggregation, and improve plant health by increasing protection against biotic (pathogen attacks) and abiotic (drought, salinity and heavy metals) stresses (Rillig \& Mummey 2006). Indeed, ectomycorrhizal fungi enhance water uptake under dry conditions by exploring a larger volume of soil than non-mycorrhizal roots, and hyphae can enter small soil pores that are not accessible to the short roots of a plant (Lehto \& Zwiazek 2011) thus improving plant water relations under low water conditions (Dunabeitia et al. 2004).

In natural conditions, Atlas cedar trees develop symbiotic associations with many different ectomycorrhizal species (Hocine et al. 1994). However, it is difficult to form mycorrhizae even after artificial inoculations. Therefore, the application of the inoculum to Atlas cedar has been limited by the difficulty in obtaining a widespread and reproducible colonisation of root systems after their inoculation by mycelia of different fungal species (Nezzar-Hocine 1998).

Abourouh (2000) and Lamhamedi et al. (2009) reported that no comprehensive studies have yet been conducted to assess the mycorrhization of Atlas cedar seedlings with spores collected from the same site and their possible behaviour in nursery. There have been few studies associated with the benefit of ectomycorrhizal symbiosis to Cedrus atlantica under water stress and it is not yet known how the mycorrhizae play an important role in the growth and water relations of forest trees.

Inoculation of Atlas cedar plants using ectomycorrhizal spores collected from the same seed collection site and soil is a more efficient technique for reaching a satisfactory mycorrhization rate in the nursery. In this way, the spore inoculation may ultimately provide an inexpensive and viable strategy for nursery growers that they can integrate easily into nursery operations for forest trees. In addition, unlike solid and liquid inoculum where only one strain (i.e. a genotype) is used, the spore inoculum allows the introduction of a variety of fungal genotypes and increase of the probability of obtaining compatible genotypes (fungus-cedar) that can promote good colonisation of the roots.

The inoculation of Atlas cedar seedlings with fungal spore inoculum of Cortinarius cedretorum (R. Maire), Amanita vaginata (Fries) Vittidini and Inocybe geophylla (Pers.) had the best mycorrhization rate and improved Atlas cedar seedling growth (Gaba-Chahboub et al. 2016). Although different studies have shown that ectomycorrhizal fungi confer drought tolerance for several forest species (Lamhamedi et al. 1992;
Lehto \& Zwiazek 2011), studies concerning the effects of inoculation by spore-based Atlas cedar seedlings on growth parameters, as well as physiological and biochemical parameters in response to drought stress are limited, and little is known about the effect of ectomycorrhizal inoculation on reactive oxygen species metabolism. Therefore, the aim of this research was to determine whether mycorrhizal symbiosis minimises the damage caused by oxidative stress via the regulation of antioxidant enzymes.

We assume that inoculation of Atlas cedar seedlings with ectomycorrhizal spores enhances their growth when subjected to drought stress. The purpose of this study is to test the controlled mycorrhization of Atlas cedar seedlings by ectomycorrhizal spore inoculation under water limited conditions and to demonstrate their effectiveness on morphological, physiological and biochemical variables in Cedrus atlantica seedlings as compared to uninoculated stressed seedlings.

\section{Materials and methods \\ Study site}

The experiment was carried out in January 2013. Both soil and Atlas cedar seeds were collected from the same stand located in the Chrea National Park $\left(36^{\circ} 25^{\prime} \mathrm{N}\right.$, $2^{\circ}$ 52' E, elevation: $1600 \mathrm{~m}$, rainfall: $1400 \mathrm{~mm} /$ year) located in the north-western Tell Atlas Mountains of Algeria where prevailing winds are from the northwest and tend to be wet. The rainy period is about ten months (September to June) and the dry period typically occurs over two months, July and August. The mean maximum temperatures of hottest month oscillate between $26.3^{\circ} \mathrm{C}$ and $33.6^{\circ} \mathrm{C}$, and the mean minimum temperatures of the coldest month can vary between $0.4{ }^{\circ} \mathrm{C}$ and $7.3^{\circ} \mathrm{C}$ (Halimi 1980).

\section{Organisms and soil used in the study}

The forest soil was collected from the A1 horizon (located at depths varying between 25 to $30 \mathrm{~cm}$ in the main zone prospected by the roots) of lower Cretaceous schists that were classified as more or less clayey (Zaidi 2002). Granulometric analysis of the collected soil showed the following composition: $13.9 \%$ clay, $20.3 \%$ fine silt, $25.2 \%$ coarse silt, $2.3 \%$ fine sand and $38.2 \%$ coarse sand (Aubert 1978).The soil is slightly acid, rich in organic matter and little limestone $(1.2 \%)$ with a total carbon of $5.2 \%$, total nitrogen of $0.08 \%$ (John 1970), assimilable phosphorus $0.9 \mathrm{mg} / \mathrm{kg}$ soil (Olsen et al. 1954), organic matter of 9.1\% (Anne 1945); a pH of 5.9 and an electrical conductivity of $2.9 \mathrm{ds} / \mathrm{m}$.

The Atlas cedar seeds were collected from ten trees located within a distance of $20 \mathrm{~m}$ from each other. The seeds were surface sterilised with $30 \%$ hydrogen peroxide $\left(\mathrm{H}_{2} \mathrm{O}_{2}\right)$ for $5 \mathrm{~min}$, rinsed three times with distilled water and then stratified at $4{ }^{\circ} \mathrm{C}$ for two weeks in the dark, under semi-axenic conditions. Seeds were transferred to Petri dishes lined with wet filter paper before they were germinated in a growth chamber at $25{ }^{\circ} \mathrm{C}$ day / night and humidity of $65 \%$. 
Three ectomycorrhizal fungi were collected from the same seed collection site. These are Cortinarius cedretorum (CC), Amanita vaginata (AV) and Inocybe geophylla (IG). The fresh carpophores were gently cleaned by a small brush to remove root fragments and soil particles still adhering to them. They were dried firstly in the open air and then in an oven at $30{ }^{\circ} \mathrm{C}$ for 24 hours to remove all traces of moisture. Subsequently, they were ground using a grinder for a very short time ( 2 min). The spore inoculums were screened using a sieve with a mesh size of $200 \mu \mathrm{m}$. These spore suspension inoculums were kept in the refrigerator $\left(4^{\circ} \mathrm{C}\right)$ until use. The forest soil was sterilised by autoclaving at $120^{\circ} \mathrm{C}$ for 20 min twice over 48 hours period.

\section{Experimental design}

The experiment was conducted in a greenhouse at the National Forest Research Institute (Bainem arboretum) located at $15 \mathrm{~km}$ west of Algiers, $36^{\circ} 45^{\prime} \mathrm{N}, 3^{\circ} 25^{\prime} \mathrm{E}$ ). The randomised experimental design included four treatments side by side: three treatments that consisted of Atlas cedar seedlings each inoculated with CC, AV and IG, and a control treatment that consisted of uninoculated control seedlings. Twenty seedlings were randomly allocated to each treatment. After one month of growth in Riedacker containers (height: $17 \mathrm{~cm}$, diameter: $10 \mathrm{~cm}$ ) with a "W" or "M" shaped section (Thermoflan, Molières-Cavaillac, Le Vigan, France), each seedling was inoculated with $0.1 \mathrm{~g}$ of ground spore inoculums mixed with $250 \mathrm{~mL}$ of sterile distilled water. Using a pipette, the spore inoculum was placed at a depth of $4 \mathrm{~cm}$ in direct contact with the roots of each seedling (Abourouh 1994) for the three treated groups and seedlings of the control group were left uninoculated. All the seedlings were watered three times per week with sterile distilled water in order to maintain soil moisture levels near saturation to promote plant and fungus growth. The experiment was conducted in the greenhouse with a 16-hour day length. Day and night-time temperatures were 25 and $18{ }^{\circ} \mathrm{C}$, respectively and relative humidity was $65 \%$.

After fifteen months of growth, while all seedlings were still actively growing and kept in the same position, a drought stress treatment was applied by withholding water for thirty days. Each batch of inoculated and uninoculated seedlings was further subdivided into two batches: stressed and control seedlings. Overall, there were eight batches of seedlings: uninoculated control seedlings (UCS); uninoculated stressed seedlings (USS); inoculated control seedlings (ICS , $\mathrm{CC}_{C}, \mathrm{AV}_{\mathrm{C}}$ and $\mathrm{IG}_{\mathrm{C}}$ ); and inoculated stressed seedlings (ISS, $\mathrm{CC}_{\mathrm{S}}, \mathrm{AV}_{\mathrm{S}}$ and $\mathrm{IG}_{\mathrm{S}}$ ).

\section{Mycorrhizal colonisation and growth measurements} The extent of mycorrhizal colonisation was assessed based on the number of mycorrhizal apices, number of fine roots, and the rate of mycorrhization of the roots. These assessments were made on root systems that had been thoroughly and carefully washed to ensure that they were free of soil. Growth data (stem height, length of main root and whole plant dry mass) were collected on ten samples from each batch that had been oven dried at $80{ }^{\circ} \mathrm{C}$ for 48 hours.

\section{Measurement of physiological and biochemical variables}

Relative water content (RWC)was determined according to (Clark \& McCaig 1982). Needles were sampled randomly from the last rosette of each seedling (five replicate from each batch). Fresh weight (FW) was determined from the needles sampled in the upper part of seedlings; Turgid weight (TW) was obtained by floating the needles in tubes with deionised water for at least $48 \mathrm{~h}$ in the dark before being weighed again. Dry weight (DW) was determined after drying needles at $80^{\circ} \mathrm{C}$ for $48 \mathrm{~h}$. RWC was calculated from the following equation: $\mathrm{RWC}=[(\mathrm{FW}-\mathrm{DW}) /(\mathrm{TW}-\mathrm{DW})] \times 100$.

Biochemical analysis was done on samples of fresh needles that were collected from the upper part of five seedlings from each batch (five replicates from five seedlings for each biochemical variable). Chlorophyll and carotenoid contents were determined in $80 \%$ acetone extract. The absorbance readings were obtained at $663 \mathrm{~nm}$ (Chlorophyll a), 647 (Chlorophyll b) and 470 $\mathrm{nm}$ (carotenoids) by an Optizen Pop spectrophotometer and contents were calculated according to Lichtenthaler (1987). The soluble sugars and starch contents were determined using anthrone reagent (McCready et al. 1950). Proline content was estimated by the method described in Rasio et al. (1987); absorbance was read at $528 \mathrm{~nm}$. Proline content was expressed as $\mu$ mole proline/g of dry matter (DM). Lipid peroxidation was determined by measuring the amount of Malondialdehyde (MDA) produced by the thiobarbituric acid reaction (Alia et al. 1995).

\section{Antioxidant enzyme activity assay}

Catalase (CAT, EC 1.11.1.6) activity was assayed by measuring the rate of disappearance of $\mathrm{H}_{2} \mathrm{O}_{2}$ according to the method described in Aebi et al. (1983). $150 \mathrm{mg}$ of fresh vegetal material was ground with $1 \mathrm{~mL}$ of $0.1 \mathrm{M}$ Tris$\mathrm{HCl}$ buffer $(\mathrm{pH}=8.1)$ and the mixture was centrifuged at $12,000 \mathrm{rpm}$. For the assay of the enzymatic activity. 100 $\mu \mathrm{L}$ of the supernatant was added to $2 \mathrm{~mL}$ of potassium phosphate buffer $(0.1 \mathrm{M}, \mathrm{pH}=7)$ and the optical density was read by adding $20 \mu \mathrm{L} \mathrm{H}_{2} \mathrm{O}_{2}$ at $6 \%$ every 30 seconds over the course of 3 to 4 minutes. The enzyme activity was expressed in $U \mathrm{mg}^{-1}$ protein $\left(\mathrm{U}=1 \mu \mathrm{M}\right.$ of $\mathrm{H}_{2} \mathrm{O}_{2}$ reduction $\mathrm{min}^{-1} \mathrm{mg}^{-1}$ protein).

Total ascorbate peroxydase (APX, EC 1.11.1.1) activity was assayed according to Nakano \& Asada (1981). The reaction was started with the addition of $\mathrm{H}_{2} \mathrm{O}_{2}$, and ascorbate oxidation measured at $290 \mathrm{~nm}$ for one minute; a decline in optical density is proportional to enzyme activity. Total superoxide dismutase (SOD, EC1.15.1.1) assay was performed according to Marklund (1974) with some modifications. The evaluation of the autooxidation of pyrogallol was carried out by differential measurement between a control and a test at $420 \mathrm{~nm}$ every thirty seconds for four minutes.

\section{Statistical analysis}

The data from these measurements and assays were subjected to a descriptive statistical analysis and analysis of variance (ANOVA). The two-way ANOVA included two 
fixed factors (inoculum and water stress), and means were compared according to the method of Newman and Keuls (Dagnelie 1999). All analyses were undertaken using the Statistica software (TIBCO Software Inc, Palo Alto, USA).

\section{Results}

\section{Effect of mycorrhization on Atlas cedar seedlings} growing under drought stress conditions

For uninoculated seedlings, significant reductions in seedling height (57\%), length of the main root (20.8\%), dry weight of whole seedling (42\%) and number of fine roots (53.8\%) were observed in stressed seedlings (USS) compared with control seedlings (UCS). Relative to uninoculated stressed seedlings, stressed seedlings that had been inoculated all had significantly higher values of the size and morphological characteristics that were measured. For example, values of seedling height in the $\mathrm{CC}_{\mathrm{S}}, \mathrm{AV}_{\mathrm{S}}$ and $\mathrm{IG}_{\mathrm{s}}$ were $191 \%, 171 \%$ and $125 \%$ greater, respectively compared with USS. The mean length of the main root in inoculated stressed seedlings was also significantly higher compared to uninoculated stressed seedlings. In the $\mathrm{CC}_{\mathrm{s}}, \mathrm{AV}_{\mathrm{s}}$ and $\mathrm{IG}_{\mathrm{s}}$ treatments, mean root lengths were $108 \%, 68 \%$ and $52.8 \%$ greater, respectively compared with USS. We found highly significant increases in the average number of fine roots between USS and ISS. These enhancement rates were:130\%, 100\% and 52.3\%, respectively in $\mathrm{CC}_{\mathrm{S}}, \mathrm{AV}_{\mathrm{S}}$ and $\mathrm{IG}_{\mathrm{S}}$ compared to USS. There was no reduction in mycorrhization rate or the number of mycorrhizal apices number in ISS compared to ICS (Table. 1).

\section{Effect of drought stress on relative water content (RWC)}

In UCS, the relative water content was $83 \%$ while in USS it was reduced significantly to $60 \%$ reflecting the installation of physiological drought. In ICS, RWC was higher than in UCS; they were $88 \%, 87.7 \%$ and $86.8 \%$, respectively in $\mathrm{CC}_{C}, \mathrm{AV}_{\mathrm{C}}$ and $\mathrm{IG}_{\mathrm{C}}$. Moreover, ISS maintained their water status and their RWC were near to that of ICS; we registered $86 \%, 85.9 \%$, and $84.7 \%$, respectively, for $\mathrm{CC}_{\mathrm{S}}, \mathrm{AV}_{\mathrm{S}}$ and $\mathrm{IG}_{\mathrm{S}}$ (Fig. 1).

\section{Total chlorophyll content (chla+b)}

In the needles of UCS, the total chlorophyll content was $225 \pm 0.007 \mu \mathrm{g} / \mathrm{g} D W$. This content increased significantly and reached $278 \pm 0.002 \mu \mathrm{g} / \mathrm{g}$ DW, $263 \pm 0.004 \mu \mathrm{g} / \mathrm{g}$ DW and $253 \pm 0.004 \mu \mathrm{g} / \mathrm{g} \mathrm{DW}$, respectively, in $\mathrm{CC}_{c}, \mathrm{AV}_{\mathrm{C}}$ and $\mathrm{IG}_{\mathrm{C}^{*}}$ Under drought stress, the total chlorophyll content was reduced significantly in USS $(161 \pm 0.006 \mu \mathrm{g} / \mathrm{g} \mathrm{DW})$ was $28.4 \%$ lower compared to UCS. In $\mathrm{CC}_{\mathrm{S}}$ and $\mathrm{AV}_{\mathrm{S}}$, the total chlorophyll content was $255 \pm 0,003 \mu \mathrm{g} / \mathrm{g}$ DW and $243 \pm 0.006 \mu \mathrm{g} / \mathrm{g}$ DW, respectively, and were significantly higher than values recorded in USS (Fig. 1).

\section{Carotenoid content}

Needle carotenoid content in $\mathrm{CC}_{c}, \mathrm{AV}_{C}, \mathrm{IG}_{C}$ were $50.4 \pm$ $0.09 \mu \mathrm{g} / \mathrm{g}$ DW, $49.6 \pm 0,09 \mu \mathrm{g} / \mathrm{g}$ DW and $49 \pm 0,10 \mu \mathrm{g} / \mathrm{g}$ DW, respectively, and were significantly higher than in
UCS 7.2\%, 4.8\%, 3.6\% increase, respectively in $\mathrm{CC}_{\mathrm{C}^{\prime}}, \mathrm{AV}_{\mathrm{C}}$ and $\mathrm{IG}_{\mathrm{C}}$. In USS, carotenoid content reduced significantly to $40.6 \pm 0.05 \mu \mathrm{g} / \mathrm{DW}$. Otherwise, carotenoid contents were significantly higher in ISS; we recorded mean values of $48.6 \pm 0.03 \mu \mathrm{g} / \mathrm{g} \mathrm{DW}, 48 \pm 0.08 \mu \mathrm{g} / \mathrm{g}$ DW and $47.6 \pm$ $0.05 \mu \mathrm{g} / \mathrm{g}$ DW respectively in $\mathrm{CC}_{\mathrm{S}}, \mathrm{AV}_{\mathrm{S}}$ and $\mathrm{IG}_{\mathrm{S}}$ (Fig. 1).

\section{Malondialdehyde content}

The average MDA content in needles of UCS was $4.1 \pm$ $0.027 \mathrm{nmole} / \mathrm{mg}$ DW. This content decreased in ICS, where it was of $1.9 \pm 0.003 \mathrm{nmole} / \mathrm{mg}$ DW, $2 \pm 0.03 \mathrm{nmole} / \mathrm{mg}$ DW and $2 \pm 0.004 \mathrm{nmole} / \mathrm{mg} \mathrm{DW}$, respectively, in $\mathrm{CC}_{\mathrm{C}^{\prime}}, \mathrm{AV}_{\mathrm{C}}$ and $\mathrm{IG}_{\mathrm{C}}$ Under drought stress, we found that the average MDA content increased to $5 \pm 0.088 \mathrm{nmole} / \mathrm{mg}$ DW $(20.6 \%$ increase) in USS compared to UCS indicating that drought stress aroused lipid peroxidation. In ISS it was significantly lower than in USS with mean values of $3.5 \pm 0.025 \mathrm{nmole} /$ mg DW, $3.6 \pm 0.075 \mathrm{nmole} / \mathrm{mg}$ DW; $3.6 \pm 0.02 \mathrm{nmole} / \mathrm{mg}$ DW, respectively, in $\mathrm{CC}_{\mathrm{S}}, \mathrm{AV}_{\mathrm{S}}$ and $\mathrm{IG}_{\mathrm{S}}$ reductions of $28.8 \%$, $27 \%$ and $26.4 \%$, respectively) (Fig. 1).

\section{Soluble sugars}

The soluble sugars content in the needles of UCS was 1.9 $\pm 0.007 \mathrm{mg} / \mathrm{g}$ DW. This content increased significantly in ICS where mean values of $2.2 \pm 0.012 \mathrm{mg} / \mathrm{g}$ DW, $2.1 \pm$ $0.006 \mathrm{mg} / \mathrm{g}$ DW and $2.1 \pm 0.006 \mathrm{mg} / \mathrm{g} \mathrm{DW}$, respectively, were obtained for $\mathrm{CC}_{C}, \mathrm{AV}_{\mathrm{C}}$ and $\mathrm{IG}_{\mathrm{C}}$ (Fig. 1). These corresponded to increases of $15.9 \%, 13 \%$ and $11 \%$, respectively. For the USS, the soluble sugars content was significantly lower than in ISS. Mean values of $2.1 \pm$ $0.14 \mathrm{mg} / \mathrm{g} \mathrm{DW}, 2 \pm 0.057 \mathrm{mg} / \mathrm{g}$ DW and $1.9 \pm 0.006$ $\mathrm{mg} / \mathrm{g} \mathrm{DW}$, respectively were obtained for $\mathrm{CC}_{\mathrm{S}}, \mathrm{AV}_{\mathrm{S}}$ and $\mathrm{IG}_{\mathrm{S}^{*}}$ Compared with USS, these contents corresponded to decreases of $41.8 \%, 39.5 \%$ and $38 \%$, respectively.

\section{Starch content}

There was no significant difference in starch content between ICS and ISS. The following mean values were recorded for $\mathrm{CC}_{\mathrm{S}}, \mathrm{AV}_{\mathrm{S}}$ and $\mathrm{IG}_{\mathrm{s}}: 1.8 \pm 0.006 \mathrm{mg} / \mathrm{g} \mathrm{DW}, 1.7 \pm$ $0.005 \mathrm{mg} / \mathrm{g} \mathrm{DW}$, and $1.7 \pm 0.006 \mathrm{mg} / \mathrm{g} \mathrm{DW}$, respectively. Small differences in starch content seemed were observed between UCS and USS $(1.5 \pm 0.01 \mathrm{mg} / \mathrm{g}$ DW and $1.3 \pm 0.008 \mathrm{mg} / \mathrm{g}$ DW, respectively) (Fig. 1).

\section{Free proline content}

The drought stress induced a significant increase in proline content in USS, where a mean value of $8.9 \pm 0.039$ $\mu \mathrm{mole} / \mathrm{g}$ DW was recorded. This content was lower in ISS where values of $8 \pm 0.117 \mu$ mole/g DW, $8.1 \pm 0.085$ $\mu \mathrm{mole} / \mathrm{g}$ DW and $8.4 \pm 0.045 \mu \mathrm{mole} / \mathrm{g}$ DW, respectively, were recorded in $\mathrm{CC}_{\mathrm{S}}, \mathrm{AV}_{\mathrm{S}}$ and $\mathrm{IG}_{\mathrm{S}}$ corresponding to decreases of $11 \%, 9.3 \%, 5.1 \%$, respectively), but still higher than values observed in ICS (Fig.1).

\section{CAT activity}

There were no significant differences between the CAT activity of needles in inoculated and uninoculated seedlings control and stressed seedlings. In ISS, the CAT activity was $95 \pm 0.02 \mu$ mole $\mathrm{H}_{2} \mathrm{O}_{2} \mathrm{~min}^{-1} \mathrm{mg}^{-1}$ protein, $95 \pm 0.01 \mu$ mole $\mathrm{H}_{2} \mathrm{O}_{2} \mathrm{~min}^{-1} \mathrm{mg}^{-1}$ protein and $96 \pm 0.01 \mu$ mole $\mathrm{H}_{2} \mathrm{O}_{2}$ min $^{-1}$ $\mathrm{mg}^{-1}$ protein, respectively, in $\mathrm{CC}_{\mathrm{S}}, \mathrm{AV}_{\mathrm{S}}$ and $\mathrm{IG}_{\mathrm{S}}$ (Fig. 1). 


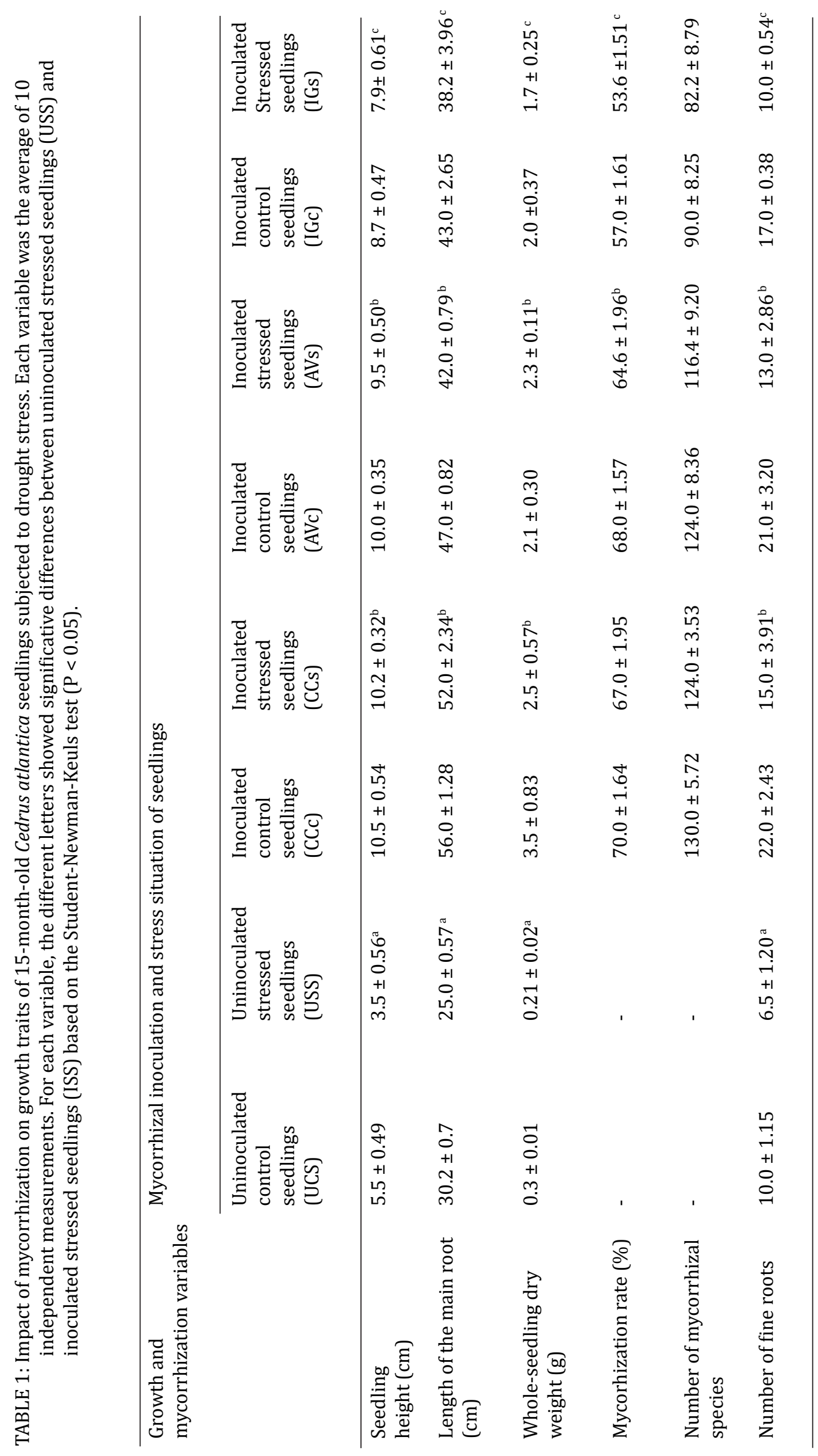



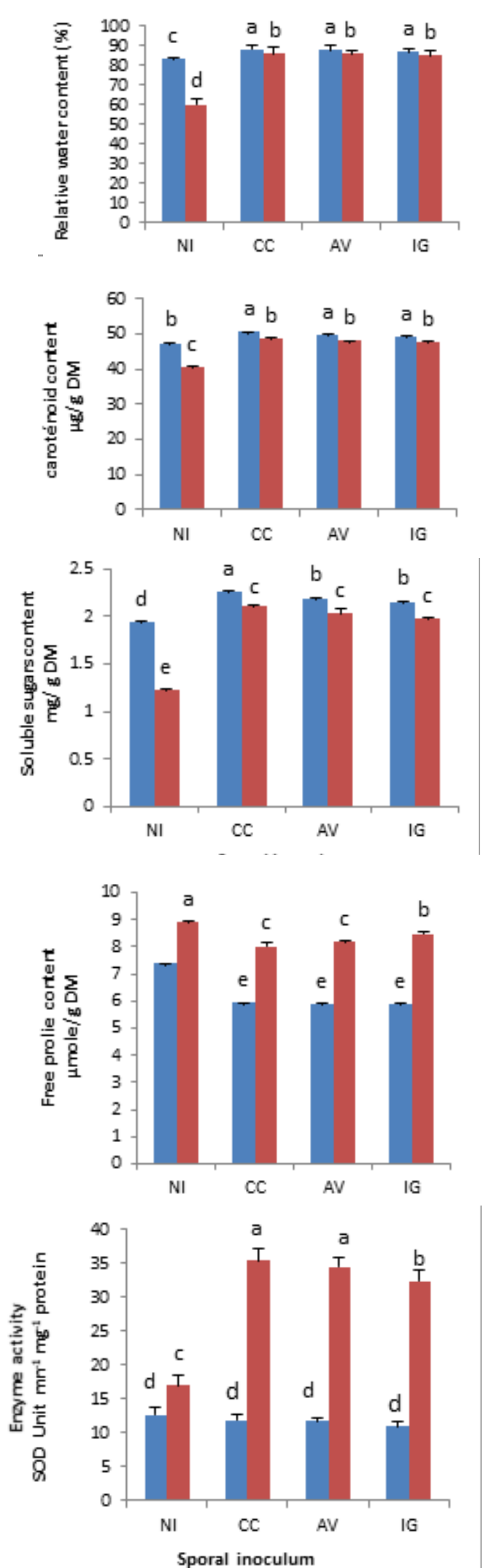

a Control seedlings

ntressed seedlings
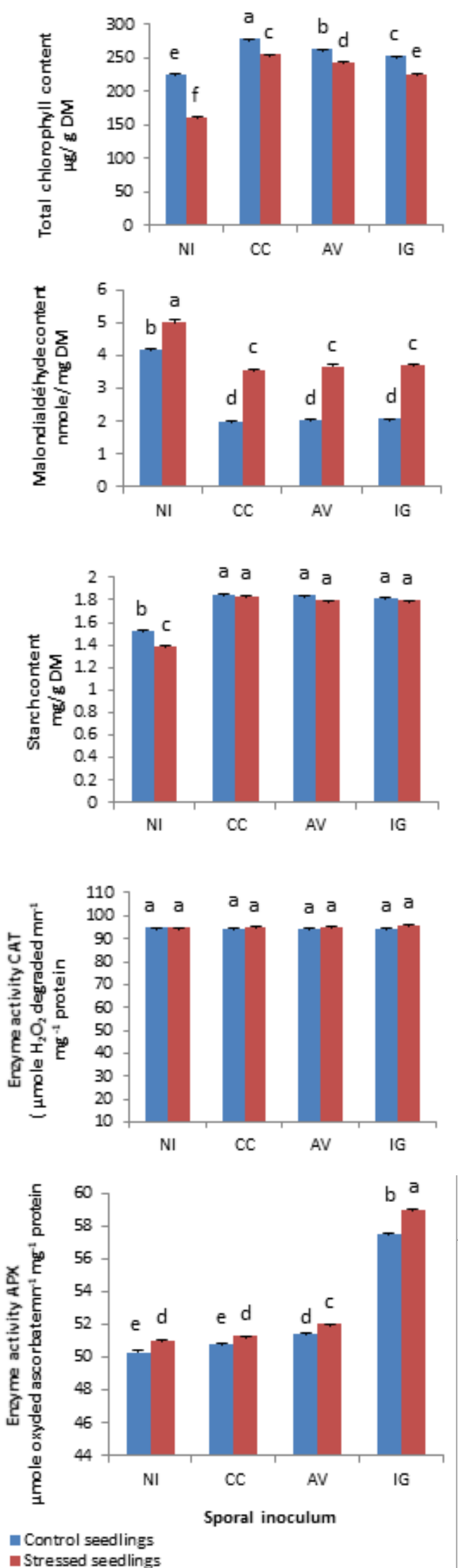

FIGURE 1: Impact of mycorrhization on physiological and biochemical variables of Cedrus atlantica seedlings under drought stress (NI: uninoculated seedlings, CC.: seedlings inoculated with Cortinarius cedretorum, AV: seedlings inoculated with Amanita vaginata, IG: seedlings inoculated with Inocybe geophylla).(five replicates for each parameter) Letters indicate the significant differences between batches of seedlings, homogeneous groups have approximatively the same mean values and the same letter following the Newman- Keuls test $(\mathrm{P}<0.05)$. 


\section{Total APX activity}

Results showed that the highest needle APX activity was observed in $I_{S}$ and $I_{G}$. However, no significant differences were observed between these two treatment groups. The increase of APX activity was approximately $13.5 \%$ in $\mathrm{IG}_{\mathrm{S}}$ compared to USS (Fig. 1).

\section{Total SOD activity}

Among the uninoculated and inoculated seedlings, SOD activity of needles in ISS was significantly higher than in ICS. Mean values of SOD activity of $35.4 \mathrm{U} \mathrm{mg}^{-1}$ protein $\mathrm{min}^{-1}, 34.5 \mathrm{U} \mathrm{mg}^{-1}$ protein $\mathrm{min}^{-1}$ and $32.3 \mathrm{U} \mathrm{mg}^{-1}$ protein $\mathrm{min}^{-1}$, respectively, were observed in $\mathrm{CC}_{\mathrm{S}}, \mathrm{AV}_{\mathrm{S}}$ and $\mathrm{IG}_{\mathrm{s}}$. No significant differences in SOD activity were observed between UCS and ICS (Fig.1).

\section{Discussion}

Our results showed that inoculated stressed seedlings had better growth than the uninoculated stressed seedling. This enhancement occurred for all growth variables recorded in this study: seedling height, length of the main root, total dry matter and number of fine roots. An increase of the ratio of the length of the main root to the height of seedlings was also observed.

The adaptation of Atlas cedar to drought is due to the extensive root growth, its ability to explore the soil thoroughly and the alternating waves of aerial growth with waves of growth root (Ducrey 1994). Thus, it has been showed in some forest species as Cedrus atlantica (Aussenac 1985), Pinus ponderosa (McMillin 1995) and Fagus sylvatica (Van Hees 1997) that water constraint induces preferentially high biomass allocation to the roots when the stress intensity is important. The enhancement of the root part at the expense of the aerial part is considered as a criterion for drought resistance (Pallardy 1993; Liu et al. 2014). In another study, plant tolerance to drought could be primarily due to a large volume of soil explored by roots and the extra-radical hyphae of the fungi (Songsri et al. 2008, Kambiranda et al. 2011, Zhang et al. 2016). Cedar trees can be considered as an anisohydric species because they are adapted to short episodic drought (McDowell et al. 2008). Atlas cedar is characterised by a very high dynamic potential of water absorption by roots, which colonise mainly the upper layers of soil. In addition, cedar plants respond quickly to rainfall via the efficiency of its ectomycorrhizal root system at 20 to $50 \mathrm{~cm}$ of depth. Under water stress, Atlas cedar maintains its physiological activity up to very pronounced drought levels (Bouahmed et al. 2019).

Relative water content is a key indicator of cell and tissue hydration, and it is important for optimal physiological functioning and the growth processes (Altinkut et al .2001). In our study, the RWC of ISS is higher than that of USS. This confirms the effectiveness of the three-spore inoculum on the upkeep of a high RWC in the needles of inoculated seedlings. Our results also showed that the total chlorophyll content $(\mathrm{a}+\mathrm{b})$ and carotenoids content decreased significantly in USS and that total chlorophyll and carotenoids content in the needles of ISS are significantly higher than those of USS. This suggests that there is a beneficial effect of mycorrhizal symbiosis on the induction chlorophyll and carotenoids accumulation (Baslam et al. 2011). Similar results were obtained in six-month-old Pseudotsuga menziesii plants inoculated with the ectomycorrhizal fungus Rhizopogon vinicolor and subjected to water stress conditions, which had higher chlorophyll levels than the stressed uninoculated plants (Dixon \& HiolHiol, 1992).

The ISS also reacted by significantly increasing soluble sugars and starch content compared to USS. Indeed, the relative increase in soluble sugars content could contribute to an osmotic adjustment that would allow the plant to balance its water content and to maintain a high cellular integrity in plant tissues during water deficit periods (Rai 2002; Chaves et al. 2003). Proline accumulation under stress conditions is due to the induction of the gene encoding the enzyme P5CS (pyrroline-5-carboxylatesynthetase) and inhibition of the proline dehydrogenase (ProDH) gene (Szabados \& Savouré 2010). The accumulation of proline is concomitant with soluble sugars in some plant species (Clifford et al. 1998) and the ability of some genotypes to accumulate the osmotica (proline and sugars) is used as a selection criterion of drought tolerant genotypes (Nouri 2002).

Mycorrhizal symbiosis protects plants against a variety of abiotic stresses using various processes such as improved photosynthetic rate, uptake and accumulation of mineral nutrients, accumulation of osmo-protectants and changes in the rhizosphere ecosystem (Yin et al. 2016). It is known that drought stress induces oxidative stress with the generation of reactive oxygen species (ROS). They attack the membrane polyunsaturated fatty acids (PUFA) resulting in their breakdown into small hydrocarbon fragments like ketones or Malondialdehyde (MDA) or other related products (Zeriri et al. 2012). In our study, MDA content of leaves in USS was significantly higher than that of ISS. In previous studies, it was reported that mycorrhizal plants had lower MDA content than non-mycorrhizal plants, suggesting that mycorrhization decreased lipids oxidative damages during stress conditions (Wu et al. 2006).

Our experiments on antioxidant enzymatic activities CAT, APX and SOD indicated that applied drought stress to Atlas cedar seedlings did not significantly modify the CAT enzyme activity and that the highest needle APX activity was observed in $I_{S}$ and $I_{C^{\prime}}$, while the highest needle SOD activities were observed in inoculated stressed seedlings relative to USS. It is known that when plants are subjected to stress, the first reactive oxygen species (ROS) scavenging enzyme active in the enzymatic mechanism is SOD which plays a key role in cellular defences against ROS (Scandalios 1993). The increase of SOD activity in leaves is closely related to a higher ability to scavenge active oxygen radicals under water stress (Abedi \& Pakniyat 2010). Moreover, there is a correlation between the SOD and CAT activities because the SOD is responsible for the formation of hydrogen peroxide $\mathrm{H}_{2} \mathrm{O}_{2}$ and the increase of this last is correlated to CAT activity (Khalifa et al. 2011). 
The importance of root antioxidant enzymes in the regulation of cellular metabolism under water stress conditions has been demonstrated by Shvaleva et al. (2006). The balance between APX and CAT activities is critical for suppressing toxic levels of ROS in cells (Apel \& Hirt 2004). In most of the previous studies, mycorrhizal application enhanced the antioxidant system (Lambais et al. 2003). Increased SOD activity in mycorrhizal plants is not related to their nutritional status but is the direct effect of mycorrhizal association in response to drought treatment of the host plant (Ruiz-Lozano \& Azcon 1995). Ectomycorrhizal plants show high resistance to drought stress by preventing oxidative stress and effectively removing ROS (Bartels 2001). Coordinated activation of SOD and CAT can prevent cellular damage to the host plant during ectomycorrhizal formation between Castanea sativa Mill and Pisolithus tinctorius (Baptista et al. 2007). The increase in antioxidant enzymatic activities induced by mycorrhizae is associated with an increase in photosynthetic activity, biomass and plant nutrition. However, the stimulation of antioxidant molecules and antioxidant enzymatic activities depends on the host plant and mycorrhizal fungi (Roldan et al. 2008). It seems that mycorrhizal inoculation notably influences the activity of antioxidant enzymes in citrus leaves under water stress and an increase in the activity of antioxidant enzymes alleviates water stress (Roldán et al. 2008).

\section{Conclusions}

This study showed that inoculating Atlas cedar seedlings with ectomycorrhizal spores were effective in improving host morphological and physiological status of Atlas cedar seedlings under drought conditions. Among the three mycorrhizal fungi inoculants, Cortinarius cedretorum appears to be consistently advantageous for Cedrus atlantica seedlings. It exhibited the greatest impact on the cedar seedlings growth under water drought, followed by AV and IG; this last had the least effect on cedar seedlings, probably reflecting its poor symbiotic efficiency under these drought conditions.

This study provides interesting perspectives and a very valuable framework for further studies focusing on integrated analysis of the ectomycorrhizal symbiosis effects under drought stress. It also showed the services delivered by ectomycorrhizal symbiosis, which has important implications to forest ecosystems of Atlas cedar in water-limited environments and could potentially lead to development of an efficient conservation strategy in order to reach sustainable objectives in forest ecosystem productivity of this endemic species.

\section{Competing interests}

The authors declare that they have no competing interests.

\section{Authors' contributions}

$\mathrm{CH}$ undertook the conception and design, acquisition of data, drafting of the manuscript, analysis and interpretation of data, and final approval of the version to be published. LMS critically revised the manuscript for important intellectual content. ABO interpreted data, drafted the manuscript and undertook analysis and interpretation of data.

\section{References}

Abedi, T., \& Pakniyat, H. (2010). Antioxidant enzyme changes in response to drought stress in ten cultivars of oil seed rape (Brassica napus L.). Czech Journal of Genetics and Plant Breeding, 46(1), 2734. https://doi.org/10.17221/67/2009-CJGPB

Abourouh M. (1994). Les Ectomycorhlzes du Cedre de l'atlas: Etat des Connaissances et Perspectives. Annales de la recherche forestière au Maroc. Le cèdre de l'Atlas (Cedrus atlantica, Manetti). Silva Mediterranea. Actes du Séminaire International sur le Cèdre de l'Atlas Ifrane (Maroc), 7 - 11 Juin 1993. Annales de la Recherche Forestiere au Maroc, 27(spécial), 337-348 http://www.fao.org/3/ ah002f/ah002f00.htm

Abourouh, M. (2000). Ectomycorrhization of the main forest species in Morocco. Doctoral thesis, Mohammed University, Rabat, Morocco.

Aebi, H. (1983). Catalase in vitro. oxygen radicals in biological systems. Methods in Enzymology, 105, 121-126. https://doi.org/10.1016/S00766879(84)05016-3

Alia, Prasad, K.V.S.K. \& Pardha Saradhi, P. (1995). Effect of zinc on free radicals and proline in Brassica and Cajanus. Phytochemistry, 39(1), 45-47. https://doi. org/10.1016/0031-9422(94)00919-K

Altinkut, A., Kazan, K., Ipekci, Z., \& Gozukirmizi, N. (2001). Tolerance to paraquat is correlated with the traits associated with water stress tolerance in segregating F2 populations of barley and wheat. Euphytica, 121, 81-86. https://doi. org/10.1023/A:1012067711200

Anne, P. (1945). Rapid determination of organic carbon in soils. Agronomic Annals, 15(2), 161-172.

Apel, K., \& Hirt, H. (2004). Reactive oxygen species: metabolism, oxidative stress, and signal transduction. Annual Review of Plant Biology, 55, 373-399. https://doi.org/10.1146/annurev. arplant.55.031903.141701

Aubert, G. (1978). Soil analysis methods, 2nd ed. Marseille, France: Regional Center for Educational Documentation, CRDP.

Aussenac, G. (1985). Le potentiel hydrique de l'arbre: une donnée essentielle pour la compréhension de 
l'écophysiologie des essences forestières. Science du Sol, 4, 217-226.

Baptista, P., Martins, A., Salomé Pais, M.S., Tavares, R.M., \& Lino-Neto, T. (2007). Involvement of reactive oxygen species during early stages of ectomycorrhiza establishment between Castanea and Pisolithus tinctorius. Mycorrhiza, 17, 185-193. https://doi.org/10.1007/s00572-006-0091-4

Bartels, D. (2001). Targeting detoxification pathways: an efficient approach to obtain plants with multiple stress tolerance? Trends in Plant Science, 6(7), 284-286. https://doi.org/10.1016/S13601385(01)01983-5

Baslam, M., Pascual, I., Sanchez-Diaz, M., Erro, J., GarciaMina, J.M., \& Goicoechea, N. (2011). Improvement of nutritional quality of greenhouse-grown lettuce by arbuscular mycorrhizal fungi is conditioned by the source of phosphorus nutrition. Journal of Agriculture and Food Chemistry, 59(20), 1112911140. https://doi.org/10.1021/if202445y

Belloula, S., \& Beghami, Y. (2018). Assessment of the dynamics of Atlas cedar decline (Cedrus atlantica Manetti) by remote sensing in the Aures area, Algeria. Arab World Geographer, 21(2-3), 154-167.

Bouahmed, A., Vessella, F., Schirone, B., Krouchi, F., \& Derridj, A. (2019). Modeling Cedrus atlantica potential distribution in North Africa across time: new putative glacial refugia and future range shifts under climate change. Regional Environmental Change, 19, 1667-1682. https://doi.org/10.1007/ s10113-019-01503-w

Boukcim, H., Conventi, S., \& Mousain, D. (2002). Ectomycorrhization of Cedrus atlantica under controlled conditions: efficiency of two forms of mycelial inoculum. Annals of Forest Sciences, 59, 839-846. https://doi.org/10.1051/ forest:2002082

Chaves, M.M., Maroco, J.P., \& Pereira, J.S. (2003). Understanding plant responses to drought: from genes to the whole plant. Functional Plant Biology, 30, 239-264. https://doi.org/10.1071/FP02076

Clarke, J.M., \& McCaig, T.N. (1982). Excised leaf water relation capability as an indicator of drought resistance of Triticum genotypes. Canadian Journal of Plant Science, 62, 571-578. https://doi. org/10.4141/cjps82-086

Clifford, S.C., Arndt, S.K., Corlett, J.E., Joshi, S., Sankhla, N., Popp, M., \& Jones, H.G. (1998). The role of solute accumulation, osmotic adjustment and changes in cell wall elasticity in drought tolerance in Ziziphus mauritiana (Lamk.). Journal of Experimental Botany, 49(323), 967-977. https://doi.org/10.1093/ $\mathrm{jxb} / 49.323 .967$

Dagnelie, P. (1999). Theoretical and applied statistics. Vol 2. Brussels, Belgium: One- and two-dimensional statistical inference.
Dixon, R.K., \& Hiol Hiol, F. (1992). Mineral nutrition of Pinus caribea and Eucalyptus camaldulensis inoculated with Pisolithus tinctorius and Thelephora terrestris. Communications in Soil Science and Plant Analysis, 23, 13-14. https://doi. org/10.1080/00103629209368674

Ducrey, M. (1994). Adaptation of the Atlas cedar (Cedrus atlantica Manetti) to the Mediterranean climate: ecophysiological aspects of its response to drought. Annals of Forest Research of Morocco, 27, 140-152.

Dunabeitia, M.K., Hormilla, S., Garcia-Plazaola J.I., Txarterina, K., Arteche, U., Becerril, J.M. ( 2004). Differential response of three fungal species to environmental factors and their role in the mycorhization of Pinus radiata D. Don. Mycorrhiza, 14, 11-18.

Et-tobi, M. (2008). Dendrometric and phytosanitary inventory of Azrou and Ait Youssi Lamekla cedar forests. Study of the causes of the dieback of the cedar grove of the Middle Atlas (Ifrane). Morocco. Convention FAO/ UTF/ MOR/028- HCE FLCD, Morocco, $77 \mathrm{p}$.

Gaba-Chahboub, H., Lamhamedi, M.S., \& AbrousBelbachir, O. (2016). Effect of ectomycorrhizal inoculation in the nursery on the growth and nutrition of Atlas cedar plants in Algeria. Tropical Woods and Forests, 330(4), 57-67. https://doi. org/10.19182/bft2016.330.a31319

Halimi, A. (1980). The Blideen Atlas, climate and plant layers. vol 1. Algeria: University Publication Office, $523 \mathrm{p}$.

Hocine, H., Belarbi, H., \& Perrin, R. (1994). Possibilities of mycorrhization of Cedrus atlantica Manetti. Annals of Forest Research in Morocco, 27 (special), 349361.

John, M.K. (1970). Colorimetric determination in soil and plant material with ascorbic acid. Soil Science, 68, 171-177. https://doi.org/10.1097/00010694197004000-00002

Kambiranda, D.M., Vasanthaiah, H.K.N., Katam, R., Ananga, A., Basha S.M., \& Naik, K. (2011). Impact of drought stress on peanut (Arachis hypogaea L.) productivity and food safety. In Hemanth Vasanthaiah, (Ed.), Plants and Environment (pp. 249-272). London: InTechOpen.

Khalifa, F.K., Khalil, F.A., Barakat, H.A., \& Hassan, M.M. (2011). Protective role of wheat germ and grape seed oils in chlorpyrifos-induced oxidative stress, biochemical and histological alterations in liver of rats. Australian Journal of Basic and Applied Sciences, 5(10), 54-66.

Kherchouche, D., Kalla, M., Gutierrez, E.M., Briki, A., \& Hamchi, A. (2013). Drought and decline of the Atlas cedar (Cedrus atlantica Manetti) in the Belezma Massif (Algeria). Drought, 24(2), 129-137. https:// doi.org/10.1684/sec.2013.0384 
Lambais, M.R., Ríos-Ruiz, W.F., \& Andrade, R.M. (2003). Antioxidant responses in bean (Phaseolus vulgaris) roots colonized by arbuscular mycorrhizal fungi. New Phytologist, 160(2), 421-428. https://doi. org/10.1046/j.1469-8137.2003.00881.x

Lamhamedi, M.S., Bernier, P.Y., \& Fortin, J.A. (1992). Hydraulic conductance and soil water potential at the soil-root interface of Pinus pinaster seedlings inoculated with different dikaryons of Pisolithus sp. Tree Physiology, 10, 231-244. https://doi. org/10.1093/treephys/10.3.231

Lamhamedi, M.S., Ammari, Y., Fecteau, B., Fortin, J.A., \& Margolis, H. (2000). Problem of forest nurseries in North Africa and orientation strategies. Agriculture Notebooks, 9(5), 369-380.

Lamhamedi, M.S., Abourouh, M., \& Fortin, J.A. (2009). Technological transfer: the use of ectomycorrhizal fungi in conventional and modern forest tree nursery in northern Africa. In: D. Khasa, Piché, Y. \& Coughlan, A.P. (Eds) Advances in Mycorrhizal Science and Technology (pp.139-152) Ottawa: NRC Research Press.

Lehto, T., \& Zwiazek, J.J. (2011). Ectomycorrhizas and water relations of trees. Mycorrhiza, 21, 71-90. https://doi.org/10.1007/s00572-010-0348-9

Lichtenthaler, H.K. (1987). Chlorophylls and carotenoids: Pigments of photosynthetic biomembranes. Methods in Enzymology, 148, 350-382. https://doi. org/10.1016/0076-6879(87)48036-1

Liu, P., Yin, L., Deng, X., Wang, S., Tanaka, K., \& Zhang, S. (2014). Aquaporin mediated increase in root hydraulic conductance is involved in siliconinduced improved root water uptake under osmotic stress in Sorghum bicolor L. Journal of Experimental Botany, 65(17), 4747-4756. https:// doi.org/10.1093/jxb/eru220

M'Hirit, O., \& Benzyane, M. (2006). Le Cèdre de l'Atlas: Mémoire du temps Sprimont, Belgium: Mardaga.

Marklund, S., \& Marklund, G. (1974). Involvement of the superoxide anion radical in the autoxidation of pyrogallol and a convenient assay for superoxide dismutase. European Journal of Biochemistry, 47(3), 469-474. https://doi. org/10.1111/j.1432-1033.1974.tb03714.x

McDowell, N., Pockman, W.T., Allen, C.D., Breshears, D.D., Cobb, N., Kolb, T., Plaut, J., Sperry, J., West, A., Williams D.G., \& Yepez, E.A. (2008). Mechanisms of plant survival and mortality during drought: why do some plants survive while others succumb to drought? New Phytologist, 178(4), 719-739. https:// doi.org/10.1111/j.1469-8137.2008.02436.x

McMillin, J.D., \& Wagner, M.R. (1995). Effects of water stress on biomass partitioning of ponderosa pine seedlings during primary root growth and shoot growth periods. Forest Science, 41(3), 594-610.
Miransari, M. (2009). Contribution of arbuscular mycorrhizal symbiosis to plant growth under different types of soil stress. Plant Biology, 12(4), 563-569. https://doi.org/10.1111/j.14388677.2009.00308.x

McCready, R.M., Guggoz, J., Silviera V., \& Owens, H.S. (1950). Determination of starch and amylose in vegetables. Analytical chemistry, 22(9), 1156-1158. https://doi.org/10.1021/ac60045a016

Nezzar Hocine, H. (1998). Natural mycorrhizal associations of Cedrus atlantica in the Djurdjura massif (Algeria) and controlled mycorrhization. Doctoral thesis, Blaise Pascal University, ClermontFerrand II, France.

Nouri, L. (2002). Osmotic adjustment and maintenance of photosynthetic activity in durum wheat (Triticum durum Desf.) in conditions of water deficit. Magister thesis. University of Constantine. Algeria.

Nakano, Y., \& Asada, K. (1981). Hydrogen peroxide is scavenged by ascorbate-specific peroxidase in spinach chloroplasts. Plant and Cell Physiology, 22, 867-880.

Olsen, S.R., Cole, C.V., Watanabe, F.S., \& Dean, L.A. (1954). Estimation of available phosphorus in soils by extraction with sodium bicarbonate. [Circular 939]. Washington: USDA, U.S. Government Printing Office, 1-19.

Pallardy, S.G., \& Rhoads, J.L. (1993). Morphological adaptations to drought in seedlings of deciduous angiosperms. Canadian Journal of Forest Research, 23, 1766-1774. https://doi.org/10.1139/x93-223

Rai, V.K. (2002). Role of amino acids in plant responses to stresses. Biologia Plantarum, 45, 481-487. https:// doi.org/10.1023/A:1022308229759

Rasio, A. (1987). Several mechanisms of water stress adaptation in durum wheat. Genetica Agraria, 42, $90 \mathrm{p}$.

Read, D.J., Leake, J.R., \& Perez-Morenco, J. (2004). Mycorrhizal fungi as drivers of ecosystem processes in heathland and boreal forest biomes. Canadian Journal of Botany, 82(8), 1243-1263. https://doi.org/10.1139/b04-123

Rillig, M.C., \& Mummy, D.L. (2006). Mycorrhizae and soil structure. New Phytologist, 171, 41-53. https://doi. org/10.1111/j.1469-8137.2006.01750.x

Roldán, A., Díáz-Vivancos, P., Herníndez, J.A., Carrasco, L., \& Caravaca, F. (2008). Superoxide dismutase and total peroxidase activities in relation to drought recovery performance of mycorrhizal shrub seedlings grown in an amended semiarid soil. Journal of Plant Physiology, 165, 715-722. https:// doi.org/10.1016/j.jplph.2007.02.007

Ruiz Lozano, J.M., \& Azcon, R. (1995). Hyphal contribution to water uptake in mycorrhizal plants 
as affected by the fungal species and water status. Physiologia Plantarum, 95, 472-478. https://doi. org/10.1111/j.1399-3054.1995.tb00865.x

Scandalios, L.M. (1993). Oxygen Stress and Superoxide Dismutase. Plant physiology, 101(1), 7-12. https:// doi.org/10.1104/pp.101.1.7

Shvaleva, A.L., F Costae E, Silva., Breia, E., Jouve, L., Hausman,J.F., Almeida, M.H., Maroco, J.P., Rodrigues, M.L., Pereira, J.S., \& Chaves, M.M. (2006). Metabolic responses to water deficit in two Eucalyptus globulus clones with contrasting drought sensitivity. Tree Physiology, 26 (2), 239248. https://doi.org/10.1093/treephys/26.2.239

Songsri,P.,Jogloy,S., Vorasoot,N.,Akkasaeng,C.,Patanothai, A., \& Holbrook, C.C. (2008). Root distribution of drought resistance peanut genotypes in response to drought. Journal of Agronomy and Crop Science, 194(2), 92-103. https://doi.org/10.1111/j.1439037X.2008.00296.X

Szabados, L., \& Savouré, A. (2010). Proline: a multifunctional amino acid. Trends in Plant Sciences, 15(2), 89-97. https://doi.org/10.1016/j. tplants.2009.11.009

Van Hees, A.F.M. (1997). Growth and morphology of pedunculate oak (Quercus robur L.) and beech (Fagus sylvatica L.) seedlings in relation to shading and drought. Annals of Forest Science, 54, 9-18. https://doi.org/10.1051/forest:19970102

Wu, Q.S., Xia, R.X., \& Zou, Y.N. (2006). Reactive oxygen metabolism in mycorrhizal and non-mycorrhizal citrus (Poncirus trifoliata) seedlings subjected to water stress. Journal of Plant Physiology, 163(11), 1101-1110. https://doi.org/10.1016/j. jplph.2005.09.001

Yin, N., Zhang, Z., Wang, L., \& Qian, K. (2016). Variations in organic carbon aggregation, and enzyme activities of gangue-fly ash-reconstructed soils with sludge and arbuscular mycorrhizal fungi during 6-year reclamation. Environment Science Pollution Research Institute, 23(17), 17840-17849. https:// doi.org/10.1007/s11356-016-6941-5

Zaidi, S. (2002). Natural regeneration of cedar (Cedrus atlantica Manetti) and its forest dynamics in the Blidean Atlas. Magister thesis, vegetal ecology, University of Science and Technology Houari Boumediene. Algeria.

Zeriri, I., Tadjine, A., Grara, N., Belhaouchet, N., Berrebbah, H., \& Djebar, M.R. (2012). Potential toxicity of an insecticide of the family of carbamates on a bioindicator model of the pollution the earthworm Octodrilus complanatus (Oligochaeta, Lumbricidae). Annals of Biological Research, 3(11), 5367-5373.

Zhang, X., Li, W., Fang, M., Jixian, Y., Meng, S. ( 2016). Effects of arbuscular mycorrhizal fungi inoculation on carbon and nitrogen distribution and grain yield and nutritional quality in rice (Oryza sativa L). Journal of the Science of Food and Agriculture, 97, 2919-1925. 